\title{
Inhibition of Mild Steel Corrosion in Hydrochloric Acid Solution by Ciprofloxacin Drug
}

\author{
Inemesit A. Akpan and Nnanake-Abasi O. Offiong \\ Corrosion and Materials Science Unit, Department of Chemistry, University of Uyo, PMB 1017, Akwa Ibom State, Uyo 520001, Nigeria \\ Correspondence should be addressed to Inemesit A. Akpan; iaakpanchem2007@yahoo.com
}

Received 28 March 2013; Accepted 19 May 2013

Academic Editor: Jerzy A. Szpunar

Copyright (C) 2013 I. A. Akpan and N.-A. O. Offiong. This is an open access article distributed under the Creative Commons Attribution License, which permits unrestricted use, distribution, and reproduction in any medium, provided the original work is properly cited.

\begin{abstract}
The inhibition of mild steel corrosion in hydrochloric acid solution by ciprofloxacin drug as an eco-friendly and commercially available inhibitor was studied at room temperature by weight loss technique. It was found that the test drug has a promising inhibitory action against corrosion of mild steel in the medium investigated. The inhibition efficiency was found to increase with a corresponding increase in the concentration of the inhibitor. It was also found that the adsorption as well as the inhibition process followed a first-order kinetics and obeyed Langmuir's adsorption isotherm.
\end{abstract}

\section{Introduction}

Mild steel is extensively used in industries and as a result corrodes when exposed to various industrial environments and conditions. The application of inhibitors has been said to be amongst the most practicable ways for protection of metals against corrosion, especially in acidic media [1-3].

The inhibitive reactivity of an inhibitor is fundamentally affected by the molecular structure of the inhibiting molecules $[4,5]$. Most prominent corrosion inhibitors are organic compounds containing nitrogen, sulphur, oxygen, and phosphorus in their functional groups [6-9]. The mechanism of these compounds has been proposed to be the adsorption, by means of lone pairs of electron, of the organic functional groups on the metal surfaces [10]. Furthermore, a good number of drugs are known to posses most of these qualities, and current research has been geared to identify cheap drugs, which are environmentally safe as corrosion inhibitors [11, 12].

The objective of this present work is to study the inhibition of mild steel corrosion in $\mathrm{HCl}$ solution by ciprofloxacin drug by weight loss method.

\section{Experimental}

2.1. Materials. A commercially available grade of mild steel (purity $=98 \% \mathrm{Fe}$ ) identified and obtained locally was employed in this study. The sheets of metal were mechanically press cut into coupons of $3 \mathrm{~cm} \times 3 \mathrm{~cm} \times 0.1 \mathrm{~cm}$ dimensions. A small hole of about $5 \mathrm{~mm}$ diameter near the upper edge of the coupons was made to help hold them with grass hooks and suspend them into the corrosive medium. The coupons were used without further polishing. However, they were degreased in acetone, washed in doubly distilled water, and stored in moisture-free desiccators before use.

The inhibitor used in this study was an antibiotic drug with common name: ciprofloxacin, while its systematic name is 1-cyclopropyl-6-fluoro-4-oxo-7-(piperazin-1-yl)quinoline-3-carboxylic acid. The molecular formula of the drug is $\mathrm{C}_{17} \mathrm{H}_{18} \mathrm{FN}_{3} \mathrm{O}_{3}$ with molecular mass of $331.346 \mathrm{~g} / \mathrm{moL}$. Ciprofloxacin has the chemical structure shown in Figure 1.

The tablets of ciprofloxacin were obtained from a local pharmacy and were used without further purification or modification. From the mass of the drug samples and it's 


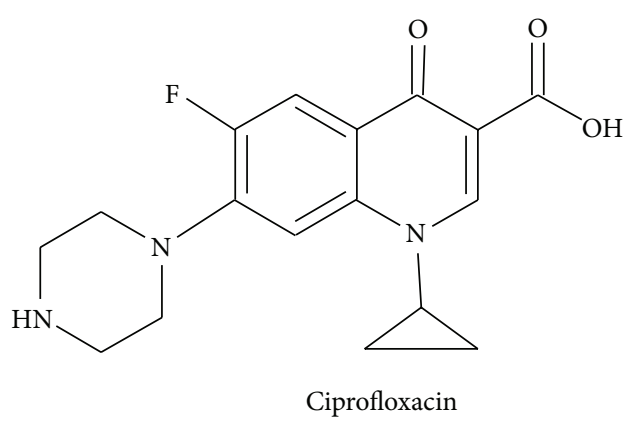

FIgURE 1: Chemical structure of ciprofloxacin drug.

molecular weight relation, appropriate concentrations of the drug were prepared by dilution.

The corrosive medium used was $0.1 \mathrm{M}$ solution of hydrochloric acid. It was prepared by appropriate dilution of analytical grade of the acid reagent with doubly distilled deionised water without further purification.

2.2. Weight Loss Measurements. In the weight loss experiment, five plastic containers of $250 \mathrm{~mL}$ capacity were labelled A to $\mathrm{E}$, each containing $0.1 \mathrm{M}$ of $\mathrm{HCl}$ solution. The first beaker was reserved as blank while each of the four remaining beakers contained the drug at different concentrations all placed at room temperature (about $30^{\circ} \mathrm{C}$ ). The metal coupons were immersed in the experimental solutions with the help of glass hooks and monitored daily (after 24 hours). The weights of the specimens were noted before immersion. After every immersion time of 24 hours, the specimens were removed, polished with emery papers, washed in double distilled water, degreased with acetone, dried in warm air, and reweighed. From the initial and final weights of the specimens, the loss of weights was calculated, and the corrosion rate (in mpy ${ }^{-1}$ millimetre penetration per year) was computed from the following equation $[13,14]$ :

$$
\text { Corrosion rate, } \mathrm{CR}=\frac{534 W}{D A t} \text {, }
$$

where $W$ is the weight loss (g), $D$ is the density of the specimen $\left(7.85 \mathrm{~g} / \mathrm{cm}^{3}\right), A$ is the surface area of specimen $\left(\mathrm{cm}^{3}\right)$ and $t$ is the immersion time (days).

The efficiency of the inhibitor was computed using the following equation [15-17]:

$$
\text { Inhibition efficiency, } \% \mathrm{IE}=\frac{W_{o}-W_{1}}{W_{o}} \times 100,
$$

where $W_{o}$ is the weight loss without inhibitor and $W_{1}$ is the weight loss with inhibitor.

\section{Results and Discussions}

3.1. Weight Loss Measurements. The inhibition of mild steel corrosion in $0.1 \mathrm{M}$ solution of hydrochloric acid by a commercially available and environmentally safe antibiotic drug, ciprofloxacin, was studied at room temperature by weight loss

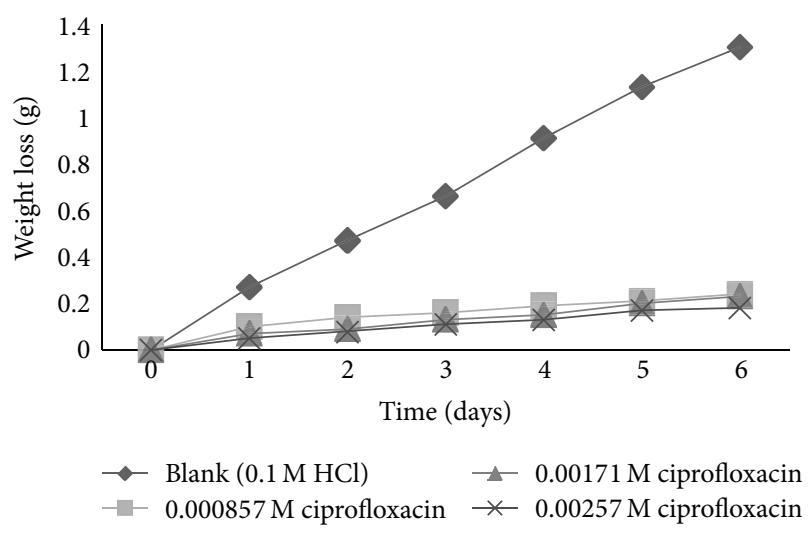

FIgURE 2: Variation of weight loss with time of exposure for corrosion mild steel in $0.1 \mathrm{M} \mathrm{HCl}$ solution in absence and presence of different concentrations of inhibitors.

technique. Results obtained from weight loss measurements are as shown in Table 1 . The result indicates that introduction of ciprofloxacin into the corrosive medium caused a significant reduction in the corrosion of mild steel. The corrosion inhibition efficiency increased with a corresponding increase in the concentration of the inhibitor. This may have resulted due to sufficient adsorption and wider coverage by the inhibitor molecules.

The calculated values for the corrosion rates (CR) are shown in Table 2 . It has been observed that the corrosion rates of the mild steel in the corrodent medium were reduced on addition of different concentrations of the inhibitor.

It has also been observed from Figure 2 that the weight loss increase as the time of exposure increased.

3.2. Kinetics of Corrosion Inhibition. Chemical kinetic treatment of the data was necessary in order to obtain information about the order of the reaction. If the concentration of the corroding metallic material is estimated in terms weight loss per volume $(\mathrm{g} / \mathrm{L})$ of the corrodent, and later converted to molar concentrations via mass of metal-molar mass of iron relation, then, the kinetics of the system may be proposed. Following the work of K. K. Sharma and L. K. Sharma [18], we assume that if $a \mathrm{~mol} / \mathrm{L}$ is the initial concentration of the mild steel $(\mathrm{Fe})$ and after time $t, x \mathrm{~mol} / \mathrm{L}$ of MS had decomposed into corrosion products. Therefore, the remaining concentration of MS at time $t=(a-x) \mathrm{mol} / \mathrm{L}$. If a plot of $\log (a-x)$ or $\log$ [MS] against $t$ gives a straight line graph, then the reaction can be said to be a first order reaction. It was based on this that we calculated for the reacted concentration of MS from weight loss measurements and obtained a graph shown in Figure 3. The shape of the graph in Figure 3 shows that the system under consideration followed a first order kinetics.

3.3. Adsorption Isotherm. Since the action of corrosion inhibitors are in most cases believed to be by adsorption on the metal surface by the inhibitor molecules using their adsorption centres, it is a good practice to find out the possible adsorption mode by testing the experimental data with several adsorption isotherms. The degree of surface coverage $(\theta)$ 
TABLE 1: Weight loss values and calculated inhibition efficiency for mild steel corrosion in $0.1 \mathrm{M} \mathrm{HCl}$ in the presence and absence of different concentrations of inhibitors.

\begin{tabular}{lccccccccccccc}
\hline $\begin{array}{l}\text { Inhibitor } \\
\text { concentration }\end{array}$ & $\begin{array}{r}\text { 1 day } \\
\text { Weight loss }\end{array}$ & IE\% & Weight loss & IE\% & Weight loss & IE\% & Weight loss & IE\% & Weight loss & IE\% & Weight loss & IE\% \\
\hline Blank & 0.27 & - & 0.47 & - & 0.66 & - & 0.91 & - & 1.13 & - & 1.30 & - \\
$0.857 \times 10^{-3} \mathrm{M}$ & 0.10 & 63 & 0.14 & 70 & 0.16 & 76 & 0.19 & 79 & 0.21 & 81 & 0.24 & 81 \\
$1.71 \times 10^{-3} \mathrm{M}$ & 0.07 & 74 & 0.09 & 81 & 0.13 & 80 & 0.15 & 84 & 0.20 & 82 & 0.23 & 82 \\
$2.570 \times 10^{-3} \mathrm{M}$ & 0.05 & 81 & 0.08 & 83 & 0.11 & 83 & 0.13 & 86 & 0.17 & 85 & 0.18 & 86 \\
\hline
\end{tabular}

TABLE 2: Calculated values of corrosion rate of mild steel in $0.1 \mathrm{M} \mathrm{HCl}$ solution in absence and presence of different concentrations of inhibitors.

\begin{tabular}{lcccc}
\hline Time (days) & \multicolumn{3}{c}{ Corrosion rate, CR (mp/y) } \\
& Blank & $0.857 \times 10^{-3} \mathrm{M}$ & $1.71 \times 10^{-3} \mathrm{M}$ & 0.0103 \\
$2.57 \times 10^{-3} \mathrm{M}$ \\
\hline 1 & 0.0399 & 0.0148 & 0.0066 & 0.0059 \\
2 & 0.0347 & 0.0103 & 0.0064 & 0.0054 \\
3 & 0.0325 & 0.0079 & 0.0062 & 0.0048 \\
4 & 0.0340 & 0.0070 & 0.0059 & 0.0050 \\
6 & 0.0333 & 0.0062 & 0.0057 & 0.0044 \\
\hline
\end{tabular}

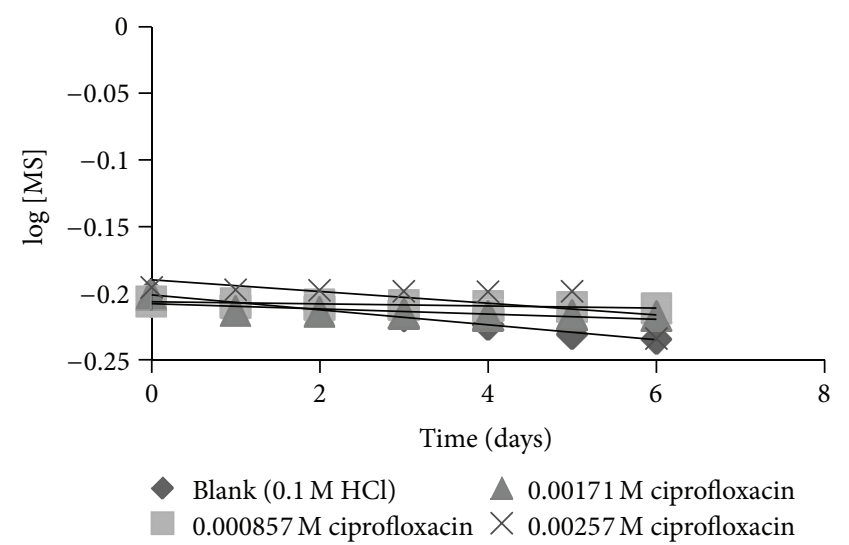

FIGURE 3: Linear plots of log of concentration of mild steel against time.

at different concentrations of the inhibitor is one of the factors considered in this test and was computed from weight loss measurements using (3) [19, 20]:

$$
\theta=\frac{W_{o}-W}{W_{o}},
$$

where $W_{\mathrm{o}}$ is the weight loss without inhibitor and $W$ is the weight loss with inhibitor:

$$
\frac{C}{\theta}=\frac{1}{k}+C
$$

where $C$ is the concentration of the corrosion inhibitor, $\theta$ is the degree of surface coverage, and $k$ is the adsorption equilibrium constant.

On consideration of the Langmuir adsorption isotherm, which is well described by (4) [21-25], it has been found that

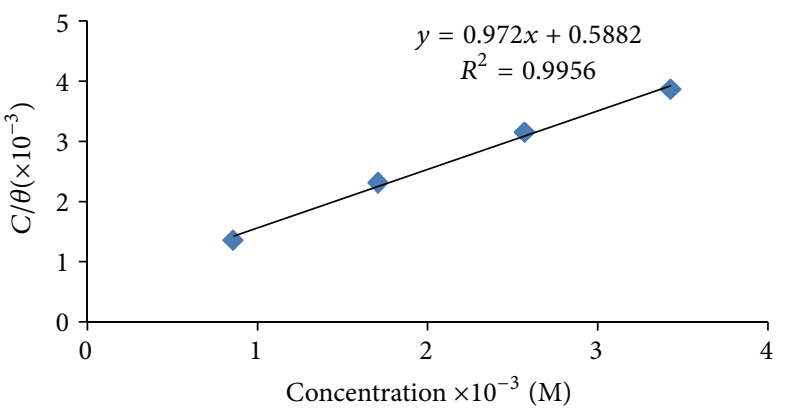

FIGURE 4: Langmuir's adsorption isotherm for mild steel in $0.1 \mathrm{M}$ $\mathrm{HCl}$ containing various concentrations of ciprofloxacin as inhibitor.

the experimental data gave a straight line graph on a plot of $C / \theta$ versus $C$ and fitted the adsorption isotherm shown in Figure 4.

The Langmuir isotherm assumes a monolayer adsorption of the inhibitor molecules on the metal surface [26].

3.4. Mechanism of Inhibition. The inhibitive action of organic compounds depends of their structure and functional groups, nature of the metal, and aggressive medium $[27,28]$. The inhibitory action of ciprofloxacin drug may be due to any or combination of the following mechanisms:

(1) physical adsorption of the molecules on the metal surface;

(2) electrostatic interactions between protonated nitrogen atoms and already adsorbed oxygen atoms;

(3) coordination due to donor-acceptor interactions between the unshared electron pairs of oxygen, fluorine, and possibly nitrogen; 
(4) the $\pi$-electrons from the aromatic rings may also interact with the vacant d-orbitals of the atoms of the metal at the interface;

(5) since the molecular weight of the compound is large, inhibition be may also be effected by hindering of attacks by aggressive species due to wider surface covered by large molecules of the inhibitor.

\section{Conclusion}

In the study of the inhibitory effect of an eco-friendly and commercially available antibiotic drug, ciprofloxacin, on the corrosion of mild steel in $0.1 \mathrm{M} \mathrm{HCl}$ via weight loss technique at room temperature $\left(30^{\circ} \mathrm{C}\right)$, the following conclusions may be drawn:

(1) the corrosion rate of mild steel reduced on addition of the test drug;

(2) the inhibition efficiency increased with an increase in the concentration of the inhibitor;

(3) the inhibition process followed a first-order kinetics;

(4) the inhibition process obeyed the Langmuir adsorption isotherm.

\section{References}

[1] P. S. Desai and S. M. Kapopara, "Inhibiting effect of anisidines on corrosion of aluminium in hydrochloric acid," Indian Journal of Chemical Technology, vol. 16, no. 6, pp. 486-491, 2009.

[2] A. S. Fouda, G. Y. Elewady, and M. N. El-Haddad, "Corrosion inhibition of carbon steel in acidic solution using some azodyes," Canadian Journal on Scientific and Industrial Research, vol. 2, no. 1, pp. 1-18, 2011.

[3] M. Ramananda Singh, K. Bhrara, and G. Singh, "The inhibitory effect of diethanolamine on corrosion of mild steel in $0.5 \mathrm{M}$ sulphuric acid medium," Portugaliae Electrochimica Acta, vol. 26, pp. 479-492, 2008.

[4] H. Ashassi-Sorkhabi and S. A. Nabavi-Amri, "Corrosion inhibition of carbon steel in petroleum/water mixtures by $\mathrm{N}$ containing compounds," Acta Chimica Slovenica, vol. 47, no. 4, pp. 507-517, 2000.

[5] I. El Ouali, B. Hammouti, A. Aouniti et al., "Thermodynamic characterisation of steel corrosion in $\mathrm{HCl}$ in the presence of 2-phenylthieno (3, 2-b) quinoxaline," Journal of Materials and Environmental Science, vol. 1, no. 1, pp. 1-8, 2010.

[6] H. P. Sachin, M. H. M. Khan, and N. S. Bhujangaiah, "Surface modification of mild steel by orthophenylenediamine and its corrosion study," International Journal of Electrochemical Science, vol. 4, no. 1, pp. 134-143, 2009.

[7] S. A. Umoren, U. M. Eduok, and E. E. Oguzie, "Corrosion inhibition of mild steel in $1 \mathrm{M} \mathrm{H}_{2} \mathrm{SO}_{4}$ by polyvinyl pyrrolidone and synergistic iodide additives," Portugaliae Electrochimica Acta, vol. 26, pp. 533-546, 2008.

[8] A. Kumar, "Corrosion inhibition of mild steel in hydrochloric acid by Sodium Lauryl Sulfate (SLS)," E-Journal of Chemistry, vol. 5, no. 2, pp. 275-280, 2008.

[9] A. K. Maayta, M. M. Fares, and A. F. Al-Shawabkeh, "Influence of linear alkylbenzene sulphonate on corrosion of iron in presence of magnetic field: kinetic and thermodynamic parameters,"
International Journal of Corrosion, vol. 2010, Article ID 156194, 9 pages, 2010.

[10] P. M. Niamien, A. Trokourey, and D. Sissouma, "Copper corrosion inhibition in $1 \mathrm{M} \mathrm{HNO}_{3}$ by 2-thiobenzylbenzimidazole: adsorption and chemical modeling of inhibition efficiency," International Journal of Research in Chemistry and Environment, vol. 2, no. 4, pp. 204-214, 2012.

[11] S. U. Ofoegbu and P. U. Ofoegbu, "Corrosion inhibition of mild steel in $0.1 \mathrm{M}$ hydrochloric acid media by chloroquine diphosphate," ARPN Journal of Engineering and Applied Sciences, vol. 7, no. 3, pp. 272-276, 2012.

[12] S. Hari Kumar and S. Karthikeyan, "Inhibition of mild steel corrosion in hydrochloric acid solution by cloxacillin drug," Journal of Materials and Environmental Science, vol. 3, no. 5, pp. 925-934, 2012.

[13] J. I. Bhat and V. Alva, "Corrosion inhibition of aluminium by 2chloronicotinic acid in $\mathrm{HCl}$ medium," Indian Journal of Chemical Technology, vol. 16, no. 3, pp. 228-233, 2009.

[14] M. Abdallah, H. E. Megahed, M. A. Radwan, and E. Abdfattah, "Polyethylene glycol compounds as corrosion inhibitors for aluminium in $0.5 \mathrm{M}$ hydrochloric acid solution," Journal of American Science, vol. 8, no. 11, pp. 49-55, 2012.

[15] I. A. Akpan and N. O. Offiong, "Effect of ethanolamine and ethylamine on the entropy content of the corrosion of mild steel in tetraoxosulphate (VI) acid solution," Chemistry and Materials Research, vol. 2, no. 7, pp. 40-47, 2012.

[16] I. A. Akpan, "Inhibitory action of bile salt on the deterioration of asbestos in acid rain," Bulletin of Pure and Applied Sciences, vol. 31, no. 2, pp. 49-58, 2012.

[17] B. S. Shylesha, T. V. Venkatesha, and B. M. Praveen, "Corrosion inhibition studies of mild steel by new inhibitor in different corrosive medium," Research Journal of Chemical Sciences, vol. 1, no. 7, pp. 46-50, 2011.

[18] K. K. Sharma and L. K. Sharma, A Textbook of Physical Chemistry, Vikas Publishing House, New Delhi, India, 1999.

[19] H. Cang, Z. Fei, J. Shao, W. Shi, and Q. Xu, "Corrosion inhibition of mild steel by Aloes extracts in $\mathrm{HCl}$ solution medium," International Journal of Electrochemical Science, vol. 8, pp. 720-734, 2013.

[20] B. M. Mistry, N. S. Patel, and S. Jauhari, "Heterocyclic organic derivatives as corrosion inhibitos for mild steel in $1 \mathrm{~N} \mathrm{HCl}$," Archives of Applied Science Research, vol. 3, no. 5, pp. 300-308, 2011.

[21] M. Mobin, M. Parveen, and M. Alam Khan, "Inhibition of mild steel corrosion in $\mathrm{HCl}$ solution using amino acid L-tryptophan," Recent Research in Science and Technology, vol. 3, no. 12, pp. 4045, 2011.

[22] M. A. Quraishi and R. Sardar, "Effect of some nitrogen and sulphur based synthetic inhibitors on corrosion inhibition of mild steel in acid solutions," Indian Journal of Chemical Technology, vol. 11, no. 1, pp. 103-107, 2004.

[23] L. A. Nnanna, V. U. Obasi, O. C. Nwadiuko, K. I. Mejeh, N. D. Ekekwe, and S. C. Udensi, "Inhibition by Newbouldia leavis leaf extract of the corrosion of aluminium in $\mathrm{HCl}$ and $\mathrm{H}_{2} \mathrm{SO}_{4}$ solutions," Archives of Applied Science Research, vol. 4, no. 1, pp. 207217, 2012.

[24] A. A. Khadom, A. S. Yaro, A. S. Altaie, and A. A. H. Kadum, "Electrochemical, activations and adsorption studies for the corrosion inhibition of low carbon steel in acidic media," Portugaliae Electrochimica Acta, vol. 27, no. 6, pp. 699-712, 2009. 
[25] O. R. M. Khalifa, A. K. Kassab, H. A. Mohamed, and S. Y. Ahmed, "Corrosion inhibition of copper and copper alloy in $3 \mathrm{M}$ nitric acid solution using organic inhibitors," Journal of American Science, vol. 6, no. 8, pp. 487-498, 2010.

[26] B. Joseph, S. John, A. Joseph, and B. Narayana, "Imidazolidine2-thione as corrosion inhibitor for mild steel in hydrochloric acid," Indian Journal of Chemical Technology, vol. 17, no. 5, pp. 366-374, 2010.

[27] S. Chitra, K. Parameswari, C. Sivakami, and A. Selvaraj, "Sulpha Schiff Bases as corrosion inhibitors for mild steel in $1 \mathrm{M}$ sulphuric acid," Chemical Engineering Research Bulletin, vol. 14, pp. 1-6, 2010.

[28] R. V. Saliyan and A. V. Adhikari, "Corrosion inhibition of mild steel in acid media by quinolinyl thiopropano hydrazone," Indian Journal of Chemical Technology, vol. 16, no. 2, pp. 162-174, 2009. 

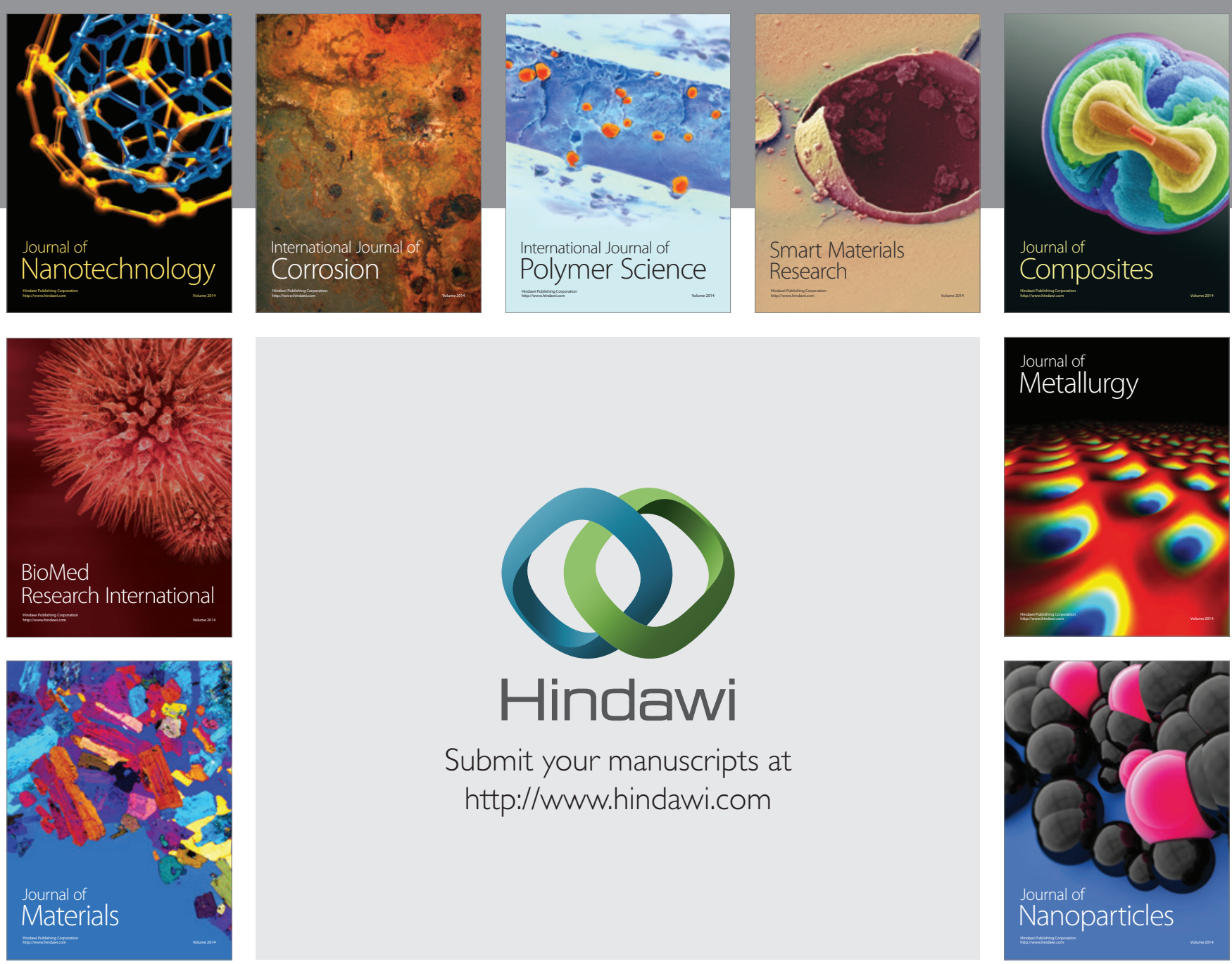

Submit your manuscripts at http://www.hindawi.com
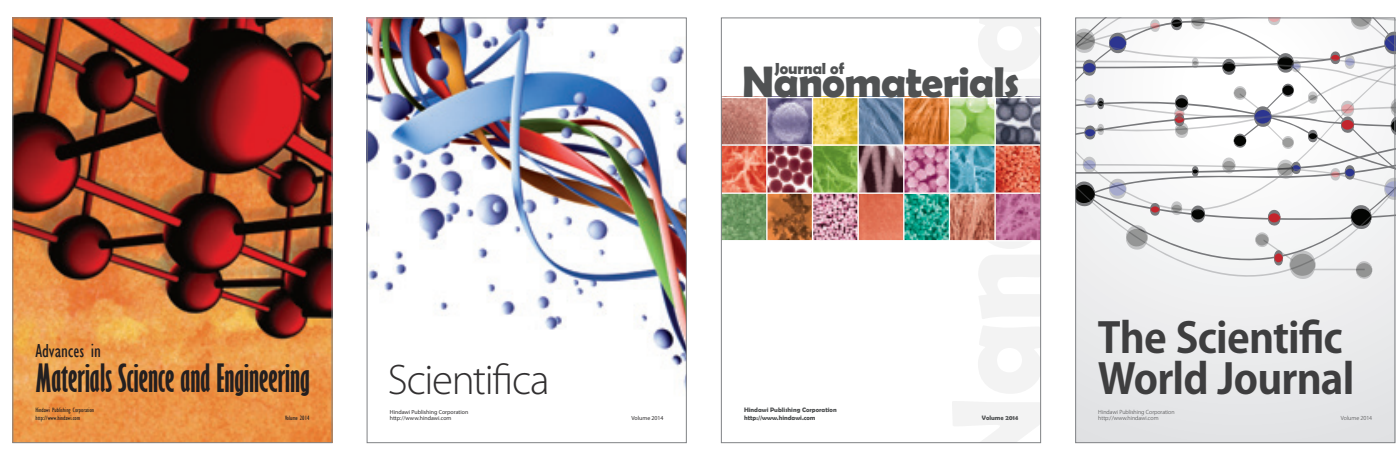

\section{The Scientific World Journal}
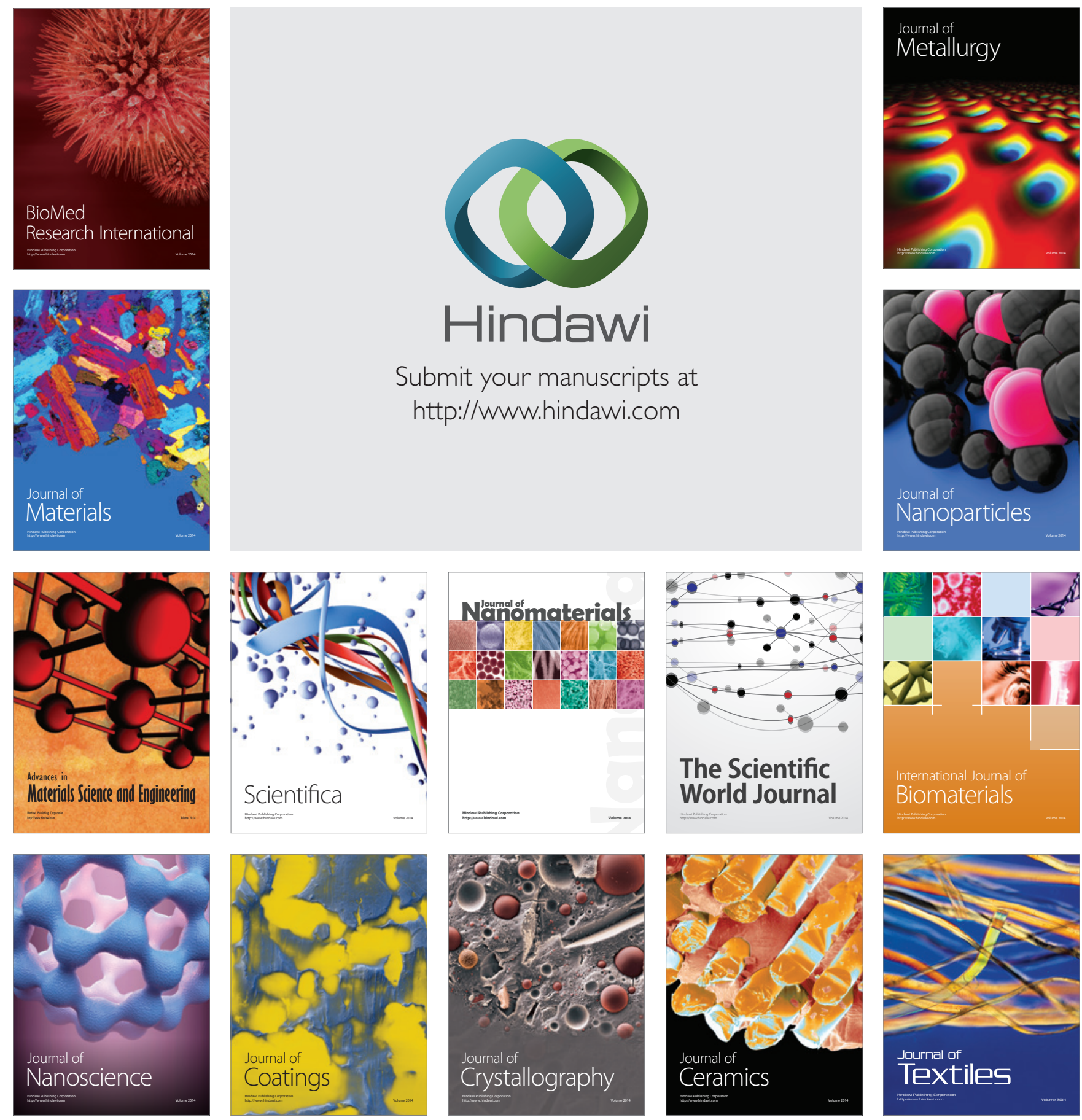